\title{
ARTIFICIO DEL ARTE \\ ESTUDIO DE ALGUNOS RELIEVES BARROCOS MEXICANOS
}

\author{
P O R \\ J ORGE ALBERTO MANRIQUE \\ Este que ves engaño colorido \\ que del arte ostentando los primores \\ con falsos silogismos de colores \\ es cauteloso engaño del sentido. \\ SOR Juana.
}

odo arte es histórico. Se encuentra dentro de ciertas normas y pre-
supuestos de su época; aun el arte más heterodoxo que podamos imaginar responde, en alguna forma, a ellos. No podemos hablar de "arte" en abstracto, sino de "arte en su tiempo", es decir, que corresponde a normas propias de su momento, emanadas de una especie de acuerdo tácito y necesario. El problema de desentrañar el sentido de unas formas artisticas reside, entonces, en encontrar el sistema de normas válidas para su tiempo.

Este sistema de normas es lo que Worringer considera como el "estilo". Antes de él la tesis generalmente aceptada suponía que el estilo era sólo un factor modificante (hasta cierto punto superficial) que alteraba la representación de la naturaleza; el gran cambio que a la interpretación de las obras de arte da el estudioso alemán es precisamente considerar el estilo como el elemento más importante de la obra, el que podrá revelarnos su sentido y hacernos descu- 
brir la circunstancia anímica de los hombres que la crearon. La representación de la naturaleza no será ya la base de la interpretación de toda obra artística, sino que ésta se basará en ese elemento, antes considerado accidental y ahora fundamental, que constituyen las normas de un momento cultural: el estilo. ${ }^{1}$

Para Justino Fernández, acorde con toda una importante corriente estética actual, no hay belleza absoluta "sino las bellezas históricas, únicos absolutismos posibles por hoy...". ${ }^{2} \mathrm{Y}$ más adelante: "la belleza no es un elemento separable de los demás de la obra de arte... nada que sea expresión de los hombres es 'puro', porque pertenece a un complejo vital." "La belleza es 'impura' porque es histórica". ${ }^{3}$

De las opiniones anteriores podemos sacar en claro que los "estilos" o "formas de belleza" tienen valor relacionados con los supuestos anímicos de un momento cultural, con las premisas básicas de determinado pathos histórico; y que, si queremos entenderlos, necesitamos relacionarlos directamente (hasta donde esto sea posible) con esa circunstancia cultural. Del mismo modo, reciprocamente, la obra de arte es reveladora de intereses vitales y es una via para descubrir y captar esa circunstancia: lo que las normas artísticas son respecto a un tiempo.

Hace aproximadamente cincuenta años que el arte producido en las colonias españolas de América empezó a ser motivo de interés para los estudiosos. De entonces a esta parte los trabajos monográficos y los estudios generales se han multiplicado y han progresado extraordinariamente en calidad. Nombres tan ilustres como el de Manuel Toussaint o el de Diego Angulo son piedras firmísimas en el ya magnífico edificio de la bibliografía al respecto. Gracias a muchos importantes investigadores, tenemos ya una visión bastante precisa de lo que es el proceso artístico de la América colonial española. Mucho queda por hacer, por aclarar, por estudiar, pero disponemos ya de una apreciación general del valor de este importante periodo artístico. Sin embargo, los estudios rebasan pocas veces el carácter descriptivo o de interpretación general. Es decir, con algunas excepciones, los estudios

1 Cf. Worringer, W.: Abstracción y Naturaleza. Trad. de Mariana Frenk, (Breviarios No 80). México, Fondo de Cultura Económica, 1953. pp. 25 ss. y 47 ss.

2 Fernández, Justino: Contlicue, estética del arte indigena antiguo. (Ediciones del IV Centenario de la Universidad, XV.) México, Universidad Nacional, 1954. Introducción, p. 17.

3 Ibid., pp. 28 y 32. 
de arte colonial americano se han desarrollado en extensión y no en profundidad. Se puede haber llegado hasta las más mínimas particularidades formales, pero se ha intentado relativamente poco desentrañar el sentido de esas formas.

Fue Toussaint quien apuntó ya esa posibilidad, pero sin llegar a sus consecuencias: “. . . logró edificarse esta pequeña maravilla (la Capilla del Rosario, en Puebla) y en ella vemos representada de tal modo la vida de la colonia, que asistimos por primera vez en la historia de nuestro país a la creación plástica de la vida de un pueblo en una forma única". "Al decir esto no se refiere Toussaint a que haya en la decoración de la capilla escenas costumbristas que representen la vida colonial, sino a que las formas ahí empleadas son expresión y representación de lo que esa vida significaba. Verdadero buceo en la profundidad (ya no sólo en la extensión) de las obras de arte de Nueva España es el emprendido por Francisco de la Maza al hacer una interpretación simbólica religiosa de ellas; pero su interés no ha sido establecer una relación directa entre las formas y ese sentido religioso. "

Un tópico muy favorecido en estos estudios es el que se refiere a la "americanidad" del arte colonial. Esto es, a la diferencia que hay -si hay alguna- entre el arte americano y el europeo. Un alto porcentaje de la bibliografía del arte colonial se mueve sobre este pivote. Y esta americanidad se ha hecho girar en torno de lo que se llama "influencia indigena". De modo que no pocas veces se han dado los autores a rastrear esos rasgos indigenas para concluir la autonomía de nuestro arte; se ha llegado incluso al absurdo de buscar posibles autores indígenas y de ahí deducir el carácter diferente de las obras; así, Angel Guido encuentra que Miguel Cabrera es un indio oaxaqueño y concluye que su pintura es la más mexicana que se produjo en la

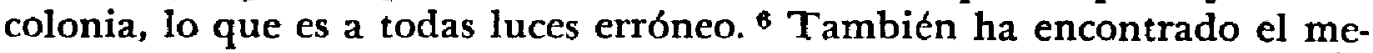
jor tipo de arte mexicano, de "arte mestizo americano" como él lo llama, al arte popular. En el mismo error se incurre cuando se piensa

4 Toussaint, Manuel: Arte Colonial en México. México, Universidad Nacional, 1949. p. 210.

5 Vid. De la Maza, Francisco: Los retablos dorados de Nueva España. México, Ediciones Mexicanas, S. A., 1959; y "La Decoración simbólica de la Capilla del Rosario de Puebla" en Anales del Instituto de Investigaciones Estéticas, Núm. 23, México, Universidad Nacional, 1955.

6 Cf. Guido, Angel: "Estimativa de la pintura colonial". Redescubrimiento de América en el Arte, Buenos Aires, Ed. "El Ateneo", 1944. 
como forzosamente más americano el arte del siglo xviIl porque está más cercano a la independencia de las colonias. ${ }^{7}$

La otra corriente (que representarian Angulo y Kubler) considera las diferencias del arte americano respecto del europeo como única y eminentemente formales, sin que estas formas vengan cargadas de otros significados. Es decir, acepta que no es igual, pero se diferencia sólo como el de una provincia (o provincias) españolas.

A pesar de que Angulo haga una introducción sobre el arte prehispánico en su Historia del Arte Hispanoamericano, y a pesar de que encuentra influencias indígenas en algunas obras (Tlalmanalco), su problema no es encontrar el carácter indigena de éstas, sino las variantes formales que hay entre lo americano y lo europeo, variantes que considera aisladamente de cualquier otro sentido, tan sólo como un accidente. Para Kubler, el arte hispano colonial no forma un mundo artístico propio, sino que está dentro del gran proceso del arte europeo coetáneo, proceso en el que ocupa un importante papel de innovador muchas veces; él ha demostrado que el carácter indigena o no indigena de los artistas o de los arquitectos no tiene ninguna importancia respecto al arte que produjeron: muestra cómo arquitectos indios llevaron a cabo obras metropolitanas, es decir, que están dentro del gran proceso de la arquitectura europea.

El problema puede plantearse de esta manera: consideramos que las obras artísticas de la América Colonial Española tienen diferencias formales con las españolas y europeas coetáneas (lo que hoy está indudablemente confirmado, por lo menos en muchos casos), y si consideramos que estas diferencias formales son fatalmente reveladoras de determinadas maneras de vida, éstas son en América diferentes en algo a las españolas. Es decir, la estructura de la sociedad, la religiosidad, la vida intelectual, el trato social, la estructura psíquica del hombre americano, era en alguna parte diferente a la correspondiente española y europea, y esto (comprobado por muchos datos históricos) produjo diferencias - diferencias formales- en el arte. Para nuestra interpretación del arte de América colonial no es de importancia fundamental discernir las causas de estas diferencias. La estructura social, razones económicas, la influencia determinante del paisaje y el elemento indígena inyectado a la cultura europea pueden haber producido este hecho histórico ( $y$ parece que no es una sola de estas fircunstancias la causa, como se supone al basar la diferencia del arte en la

7 Cf. Guido, op. cit., pp. 273 ss. y 227 ss. 
Inano de obra indigena); lo fundamental para nosotros por ahora es que esa diferencia existia, y que el arte -expresión vital-corresponde a esa peculiar manera de ser del hombre americano. $Y$ el problema a resolver es la correspondencia de esas formas artisticas con esa estructura vital, de la cual son expresión. Decimos con Worringer que "no hay más estética que la estética de las formas artísticas", pero se trata de formas que corresponden a coordenadas temporales y especiales. En contrar, pues, las convenciones propias de ese arte, y cómo es la expresión de una peculiar manera de ser, puede constituir la base de toda estética del arte colonial hispanoamericano. ${ }^{8}$

En realidad, cualquier obra producida por los artistas novohispanos puede permitirnos deducir las normas propias del arte de la Nueva España, abrirnos la entrada a ese mundo especial. Para el presente trabajo he escogido los relieves de la sillería del Coro de San Agustín de México, hoy en el Salón General de Actos ("Generalito") de la Escuela Nacional Preparatoria, en San Ildefonso, y un relieve que decora la Capilla del Rosario, en la iglesia de Santo Domingo de Pucbla, colocado bajo el gran cuadro de la Virgen que se encuentra en el testero de la capilla. Ambos - el relieve de la capilla y los de la sillería del Coro de San Agustín- son obras cuyas fechas de construcción están cercanas, ambas corresponden a los mismos supuestos plásticos, ambas son, pues, expresión de un determinado momento histórico. Es decir, que por encima de sus diferencias (el diverso material, la policromía de uno de los relieves, etcétera), ambos tienen una relación mayor que el simple hecho de ser relieves: hablan el mismo lenguaje artístico, expresan los presupuestos de un mismo mundo, de una misma manera de ser.

Del relieve de la Capilla del Rosario (el nacimiento de la Virgen) no tenemos mayores datos acerca de su realización. (Fig. 1) Sabemos sólo que fue terminado en 1690 , en que se inauguró la decoración de esta pe-

8 Vid. el importantísimo trabajo de Justino Fernández: El Relablo de los Reyes. Estética del Arte de Nueva España. México, Universidad Nacional, 1959 (Instituto de Investigaciones Estéticas. Estudios de Arte y Estética, 4), donde resume y analiza cuidadosamente las diferentes posiciones que se han adoptado frente a estas producciones artísticas, y los diferentes intentos por formar una estética del arte colonial. Ante ellos, el Dr. Fernández adopta una postura netamente historicista al afirmar que "no hay más estética del arte que las opiniones estéticas sobre las obras mismas". 
queña joya arquitectónica; ${ }^{\theta}$ el relieve del nacimiento de la Virgen es apenas un detalle dentro de la rica y exuberante decoración de la capilla, un mínimo detalle que no por eso deja de tener valor autónomo, además del significado que tiene formando parte del conjunto.

Hasta hace unos años se desconocían el autor y la fecha exacta en que fue trabajada la sillería del Coro de San Agustín. En 1948 Heinrich Berlin publicó por primera vez el contrato para hacer esta obra, que encontró en el Archivo General de la Nación. ${ }^{10}$ Por él se compromete Salvador de Ocampo "vccino de esta ciudad de México y maestro de emsamblador y entallador" a "hacer la sillería del coro del convento de San Agustín de esta dicha ciudad, con toda la labor, hechura y primor", y a entregarla un año después de firmado el contrato, esto es, en mayo de 1701. Sin embargo, Guillermo Toussaint y Romero de Terreros, entre otros, suponen que la sillería no es obra de una sola persona, y que Salvador de Ocampo fue ayudado por sus fiadores Andrés de Roa y Francisco Rodríguez, ambos "maestros de ensambladores". ${ }^{11} \mathrm{El}$ escultor Guillermo Toussaint, que fue comisionado para restaurar la silleria en 1933, dice que "Cada tabla ha sido tratada con el esmero que se dedica a una obra aislada, como si por sí sola encerrara todo el interés." 12 Y esta opinión, que nos parece acertada, nos lleva a obtener una primera conclusión: tanto los relieves de la Capilla del Rosario en Puebla, como los de la sillería de San Agustín tienen una función dentro del conjunto, pero tienen también, cada uno por sí, un valor propio, autónomo, individual.

Los relieves del coro de la iglesia de Santo Domingo, en Oaxaca, son antecedentes del estudio de la Capilla del Rosario en Puebla; a pesar de sus mayores pretenciones, encontramos en ellos Ia misma manera de trabajar el yeso y la misma estructura formal. Moreno Villa, quien ha estudiado con más detenimiento que ninguna otra persona la escultura colonial, nos dice refiriéndose a ellos: "En uno de los relieves... se repite [como en el imafronte de San Agustín] el tema

9 Vid. Gorozpe, Diego de: Octava Maravilla del Nucvo Mundo, citado por De la Maza en "Decoración simbólica..." (Supra, nota 5.)

10 Berlin, Henrich: "Salvador de Ocampo, a Mexican Sculptor" en The Americas, vol, tv. núm. 4. Washington. April, 1948.

11 Romero de Terreros, Manuel: La iglesia y convento de San Agustin, México, Universidad Nacional, 1951 (Ediciones del IV Centenario de la Universidad, II) - p. 20.

12 Cf. Silleria del Coro de la antigua iglesia de San Agustin. Con un cstudio de Rafael Garcła Granados. México, Universidad Nacional, 1941. p. 9. 
del manto cobijador. En el otro relieve hay también repetición del tema, pero con mayor libertad. La Virgen se aparece a Sto. Domingo; pero, mientras en el relieve de la fachada se mantiene a distancia, en el del coro llega a acariciarle. Aunque mirando para otro lado. Falta de unidad muy primitiva." ${ }^{13}$ Pasemos por alto que no se trata, como supone Moreno Villa, de Santo Domingo, sino de Alain de La Róche, propagador de la devoción del Rosario, y la Virgen no lo acaricia, sino que está alimentándolo "con su santísima leche", según se dice que le aconteció al santo en uno de sus éxtasis; el hecho de que voltee para otro lado es el natural pudor que el escultor no pudo evitar poner en la Virgen y en los ángeles que la rodean, que vuelven también la cara respetuosos. (Nótese que este relieve se encuentra en el coro, es decir, únicamente visible para los mismos frailes dominicos y no para todo el público.) No hay, pues, tal falta de unidad, pero sí es posible encontrar en ese relieve de mediados del siglo XVII ese ligero toque primitivo que señala Moreno Villa, a pesar de que es, a todas luces, barroco cien por ciento. Los ángeles, las nubes en forma de $S$, el movimiento todo de la escena, la policromía, el claroscuro, no son capaces de borrar ese rasgo de ingenuidad, ese carácter espontáneo que llamamos, a falta de otro nombre mejor, "primitivismo". Aunque se trata de un primitivismo que viene arrastrando siglos de experiencia.

Angulo, al referirse a la escultura mexicana de fines del siglo XVII también encuentra a menudo primitivismos; así, el relieve de la iglesia de San Agustín en México (en la fachada) le resulta de "sorprendente arcaismo", y la sillería de la catedral de México le parece: de "estilo bastante arcaizante para fines de siglo". ${ }^{14}$

Es curioso comprobar cómo nuestro arte colonial tiene siempre ese rasgo ingenuo. Si en las obras más puramente renacentistas que conservamos hay algunas que pueden escapar a él, en el periodo barroco lo encontramos casi infaliblemente. Así, pongamos la atención en las obras metropolitanas, donde la Colonia puso todo su empeño, todas sus posibilidades y el trabajo de sus mejores artistas. En algún detalle -una cabeza de ángel, el trabajo de una decoración fitomorfa, los pliegues de una vestidura, y mil otros más- aparece esa ingenuidad, ese "primitivismo". En los relieves que estudio, el de la Capilla del Rosario y el de

13 Moreno Villa, José: La escultura colonial mexicana. México, Fondo de Cultura Económica, 1942 (El Colegio de México) . p. 48.

14 Angulo fñiguez, Diego: Historia del Arte Hispanoamericano. Barcelona, Salvat Editores, S. A., 1950. vol. II, pp. 286-287. 
la sillerfa de San Agustín, está presente este rasgo; pero ni la capilla misma ni la sillería pueden ser considerados como obras populares, y sin embargo en ambas encontramos el carácter ingenuo y espontáneo. Puede decirse que hago referencia a detalles dejados a artistas inexpertos, mientras los mejores se encargaban de lo más importante de la obra; pero esto sólo en parte es cierto, porque toda la decoración de la Capilla del Rosario tiene ingenuidad. Las mismas esculturas de los dones de la Virgen, las del corito, las del crucero, todas están afectadas del mismo carácter, aunque -si se quiere- no tan marcado como en el relieve de que me ocupo. Otro tanto puede decirse de la sillería de San Agustín, que siendo toda una obra de primera importancia, encomendada a los mejores artistas del tiempo, y orgullo de la Orden, muestra el mismo "primitivismo" aun en los relieves más importantes.

Cuando Angulo y Moreno Villa hablan de "primitivismo" o de "sentido arcaizante" en las obras coloniales, podemos entender que se re. fieren a un atraso del arte de la Nueva España respecto al de Europa. El hecho de que se produjeran en Nueva España formas que hacía tiempo habían dejado de darse en el continente europeo es ya una diferencia muy importante: aun cuando solamente se trate de un retraso, esa extemporalidad de las obras artísticas novohispanas es muy significativa y constituye en sí un rasgo fundamental, una manera propia. $Y$ sin embargo, la idea del retraso no es una explicación suficiente; cualquier comparación nos permite advertir diferencias entre las formas novohispanas que llamamos afectadas de "primitivismo" y cualquier obra artística europea de siglos anteriores. Creo que los términos "primitivismo" (así, con comillas siempre) e ingenuidad, no se fuerzan al asimilarse uno a otro, como lo he hecho; los dos sirven para expresar las características formales que resultan de una cierta manera de ser. Considerar estas características como el simple resultado de una mano de obra de poca calidad es una explicación cómoda, pero poco satisfactoria; seguramente hubo en Nueva España buenos y malos artífices, pero no podemos acudir a este expediente cuando nos encontramos frente a una característica constante de este importante periodo artístico, es decir, a uno de los elementos constitutivos del arte (estilo) novohispano. Así pues, se hace necesaria una explicación de este estilo, yendo lo más a fondo que sea posible dentro de la vida de las gentes que lo crearon. ¿Quiénes lo crearon? ¿Qué concepto tenían aquellos hombres de lo que era el arte?

En relación estrecha con el sentido de ingenuidad está el carácter anónimo de las obras que estudio y de una mayoría abrumadora de pro- 
ducciones artísticas del México Colonial. La fama de la Capilla del Rosario de Puebla fue tanta que se imprimió un libro para celebrarla; ${ }^{15}$ en él se trata del simbolismo de la obra, de su importancia como "octava maravilla", pero no se cita siquiera a los artistas que trabajaron en ella, con excepción del pintor Rodríguez Carnero. Actualmente sabemos quién fue el escultor de la sillería de San Agustín, pero porque fue hallado el contrato en que se le encargaba la obra, no porque se haya querido conservar su nombre. Es así como conocemos a la mayor parte de los artistas novohispanos, por contratos, por relaciones de sus méritos y servicios en vista a solicitar nuevos encargos, etcétera, pero muy pocas veces porque se haya tenido la intención de dejar, para las generaciones futuras, el nombre del autor ligado a la obra. La excepción más notable sería la de los pintores, que rara vez dejaban de firmar sus cuadros. De todas formas, y a pesar de que las investigaciones nos revelan cada vez nuevos nombres de artistas y ayudan a completar las biografías de los ya conocidos, el arte de Nueva España es, en gran parte, anónimo.

Este anonimato viene de una diferente concepción de lo que es el arte y la obra artística. Al hombre de Nueva España no le importaba la obra como producto de su autor, no le importaba la relación obra-autor; le interesaba sí, la obra misma, autónoma, animada de vida propia. Le interesaba la obra en cuanto cumplía sus fines, pero desligada del autor, que no venía a ser más que un simple accidente. Es decir, le importaba la relación obra-espectador, la eficacia de la obra. La obra de arte cumplía una necesidad (religiosa, de lujo, etcétera) le importaba en cuanto realizaba ese fin social, no en cuanto a expresión personal del artista. Indudablemente el artista, encajado en una determinada circunstancia, al expresarse con fortuna en la obra de arte, expresaba el mundo en que vivía y convertía la obra en socialmente eficaz; pero esto, al espectador, al usufructuario, no le importaba particularmente. Para decirlo de una vez: el arte se consideraba como técnica y oficio, y al artista como artesano, lo que no implica de ningún modo rebajamiento o inferioridad de ese arte, sino sólo una concepción diferente de lo que es para nosotros (vale recordar aquí el sentido etimológico de la palabra arte). El "primitivismo" a que antes hacla referencia es un elemento más de ese anonimato y de ese sentido artístico colectivo.

Esto nos plantea uno de los problemas capitales de la vida del siglo xvi! en Nueva España. Heredera del Renacimiento y de toda una idea del

15 Vid. la obra de Gorozpe, comentada en parte por De la Maza. (Supra, nota 5.) 
individuo moderno, sin embargo, la absoluta homogeneidad religiosa y las bases económicas sobre las que se fundamentaba la sociedad tenian una gran similitud con las que rigieron en Europa en la Edad Media. Habla ese desgarramiento o por lo menos esa yuxtaposición de dos formas de vida diferentes y aun contradictorias, que daban lugar a una nueva: la vida del hombre novohispano. La contemplación de las manifestaciones vitales de ese hombre nos lo revela sorprendente y hasta paradójico; al lado de prácticas y costumbres medievales encontramos fiestas versallescas; al lado de autos sacramentales encontramos comedias galantes; al lado de discusiones teológicas escolásticas, encontramos investigaciones cientificas con sentido moderno, como es el caso de don Carlos de Sigüenza y Góngora hablando sobre los cometas, o de Sor Juana escribiendo un tratado científico sobre la música. Del mismo modo, al lado de un cultivo exaltado de la personalidad individual (los "títulos", los virreyes, los obispos, a veces los poetas) una falta de interés por los artistas plásticos, aunque no por el arte. Es la contradicción del hombre que tiene la mitad moderna y la otra medieval, que vive a caballo entre estas dos maneras diferentes que constituyen su propia manera de ser.

Hablando de las dos sillerías más importantes de la ciudad de México (la de la Catedral y la de San Agustín o del "Generalito"), Moreno Villa nos dice que "mientras la catedralicia se decide por llenar los tableros principales con figuras aisladas, según el uso del siglo XVII, la llamada del "Generalito" opta por el sistema antiguo de narrar pasajes bíblicos $y$, con ello, reunir en un solo tablero gran cantidad de elementos. Con este sistema se retrocede al plateresco, y resulta una obra más arcaica de lo que es. Su valor decorativo es mucho mayor y lo mismo su fantasía, pero, rigurosamente hablando, traiciona a su época...". ${ }^{16}$ Moreno Villa fue capaz de percibir el fenómeno pero no se detuvo a analizarlo. Los relieves de San Agustín no traicionan a su época; la traicionarían en España, pero no en México; una obra de los alcances de esta sillería no puede "traicionar una época", si no concuerda con la imagen que tenemos cle esa época es que nuestras interpretaciones no son válidas: es la obra la que nos revela la verdadera imagen de ese tiempo. El hecho de servirse de formas y modos artísticos que ya no eran vigentes en Europa, y darles una nueva vida, se explica perfectamente en Nueva España; es esa justamente una de sus características. Es la expresión del contradictorio hombre novohispano, moderno y medieval. Son las iglesias barro- 
cas que, con el repertorio formal del Renacimiento - más o menos alterado- tienen proporciones casi góticas. Es, en fin, la tónica del arte setecentista de este lado del Océano.

El arte de Nueva España tiene, casi siempre, un sentido que podríamos llamar "analítico". No es naturalista, pero conserva la idea individual de cada cosa que representa; en su expresión del mundo tienen igual importancia las cosas aparentemente más notables y las cosas más insignificantes. Hay una especie de honradez religiosa al reproducir la naturaleza y al tratar cada parte de la obra artística, cada estrofa de ese himno sacro: el mundo es creado por Dios y todas las cosas por él hechas tienen en principio el mismo valor. Años después de la época que estamos tratando, el padre Loyzaga nos platica que en 1720 , al recubrir de retablos el crucero del Santuario de Ocotlán, en Tlaxcala, se habian labrado y dorado partes que por la misma forma del retablo quedarían siempre escondidas y que ningún ojo humano veria. ${ }^{17}$ Este respeto religioso del arte lo encontramos lo mismo en la visión "analítica" de la naturaleza que representa, que en el sentido "minucioso" de la hechura de las obras. Del relieve de la fachada de la iglesia de la Encarnación, en México (siglo XVII), nuestro tan citado Moreno Villa dice que "tiene igual valor lo plástico secundario que lo principal", y que "los tiempos admitian y exigian una simplificación mayor"; 18 lo que pasa es que para el escultor de la Nueva España casi no había elementos principales y elementos secundarios, en ese sentido, y no valían las simplificaciones a que alude nuestro autor. Cuando en la sillería de San Agustín se representa un bosque (Fig. 2) está cada árbol en su individualidad y cada hoja en la suya. Para el interior de una casa no bastan ciertos elementos que permitan reconocerla, ni objetos que "den ambiente", es preciso representar la casa en su integridad, con todos los objetos que, yuxtapuestos, la constituyen. Así el tablero de la silleria que representa a Josué y la esposa de Putifar (Fig. 3) tiene las chanclas y la taza de noche

17 Como una simple comparación marginal puede recordarse aquí el relicve oculto en la base de la monumental Coatlicue del Museo Nacional de México, o las escenas de los capiteles románicos inaccesibles al ojo normal; en unos y otros encontramos el mismo sentido religioso como razón de ser del arte.

18 Moreno Villa: op. cit. p. 48. 
de la señora; o el tablero que representa la casa de Rebeca necesita el perico y los perros (Fig. 4); o en el nacimiento de la Virgen de la Capilla del Rosario, (Fig. 1) se colocan la canasta de vendas y la palangana de agua caliente. En esta visión minuciosa, analítica, del mundo, no cabía más que un intento de representación integral.

Una característica sobresaliente del arte barroco de Nueva España es su necesidad decorativa. El rico de Nueva España, rico como nunca soñó serlo, tenía la necesidad de mostrar esa riqueza, de manifestarla con signos exteriores, visibles y perdurables; he aquí una de las razones de ser del barroco. Pero también en sus relaciones respecto a Dios tenía ese hombre que mostrarse espléndido; de una relación que a cada paso era más difícilmente íntima y directa, una relación cada vez más codificada, el hombre de Nueva España -que sin embargo la sentla absolutamente sincera - tenía la necesidad de dar signos externos; la relación hombreDios, que internamente se empobrecía, tenía que manifestarse exteriormente: por eso la esplendidez, el gesticular continuo: el barroco. Cuando los últimos rincones de la conciencia no pertenecían en derecho, sino que para todo sentimiento había un sermón y una cita del Evangelio, hubo la necesidad de (en una curiosa manera de lo que llamaríamos "volver la oración por pasiva") volcarse hacia afuera, desbocarse, encontrar en formas artísticas simbolos de vivencias internas muertas en embrión. La ternura, la imaginación fantástica, el drama, todo encontró una forma convencional y espléndida que le correspondiera. Este sentido grandilocuente, fantástico, puede encontrarse en los grandes retablos o en las magnificas fachadas, pero no sólo ahí; en obras que aparentemente conservan un tono menor podemos hallarlo. Nuestros relieves (el de la Capilla del Rosario de Puebla y los de la sillería de San Agustín) lo ostentan. En el nacimiento de la Virgen el tropel de nubes y de ángeles es más grande que Santa Ana y San Joaquín, tropel que es precisamente la irrupción de lo divino en lo humano, es la presencia de lo trascendente en la natividad mariana. En los relieves de San Agustín son también las nubes, los ángeles apocalípticos, la faz de Dios mismo. Es, en ambos casos, la grandeza de lo divino que puede manifestarse en lo más humilde; pero lo divino presentado en formas grandilocuentes que lo expresen y lo hagan tangible. 
Angulo dice que los relieves de la sillería de San Agustín son: "de calidad inferior a los de la catedral, las grandes figuras de éstos son remplazadas por figuras del Antiguo Testamento, temas, como es sabido, poco frecuentes en nuestro arte, y por este motivo hacen de la sillería mexicana el repertorio plástico más rico de esa naturaleza". ${ }^{10}$ Podemos deducir cuál ha sido el criterio del historiador español para juzgar de su inferioridad: ha aplicado un criterio absolutamente naturalista.

Pero el arte de Nueva España es precisamente un arte antinaturalista. Su razón de ser consiste, en buena parte, en ese alejarse de la naturaleza. Lo que hace a los hombres como tales es su no ser naturales; el siglo XviI es el siglo del artificio, de los afeites, de los trajes que cubren totalmente el cuerpo, de las pelucas, de los chapines. El arte tendrá entonces que ser también totalmente "artificioso"; ya pasó el Renacimiento (sobre todo el Renacimiento a la europea) que es un acercamiento a lo natural, a la belleza de los cuerpos; todavia no llega el siglo xviII con sus afanes rousseaunianos y su poesía pastoril, con su idea del hombre "natural" como suma de virtudes. El hombre del siglo xvir (especialmente el hombre de Nueva España) es justamente un ejemplo de artificio: artificio en las costumbres mismas, artificio en el pensamiento. Cuando contemplamos un retrato de Correa o de Rodríguez Juárez (pienso, por ejemplo, en los retratos de canónigos de la "Aparición de San Miguel" de la sacristía de la Catedral de México, y en el retrato del duque de Linares) nos parece que son hombres que nunca existieron los que vemos representados. Tanta es su poca naturalidad. Hay una artificiosidad que alcanza a todas las formas de vida.

Se puede hablar del "engaño" del arte barroco de Nueva España. El arte barroco se interesa por la naturaleza, pero negándola en cierto sentido. La decoración barroca está llena de elementos naturales (muy a menudo elementos vegetales), pero que han sido transformados, humanizados. La naturaleza es un lejano punto de partida, de donde el barroco se provee para elaborar su mundo de formas. Los hombres de nuestro siglo xvir no alababan ya lo bien "contrahecho" (imitado de la naturaleza), como lo hicieron los del siglo xvi; ahora se aprecia la "invención

19 Angulo: op. cit. vol. II, Pp. 288-289. 
de los artífices", 20 la "variedad", la "mudanza artificiosa de los emblemas"; ${ }^{21}$ también la "perfección, adorno y lucimiento"; ${ }^{22}$ es decir, importa el partido que se pueda sacar de las formas ya dadas. El arte no es copia, sino engaño; silogismo de formas. Como tal es reconocido y aceptado. Así, Sor Juana puede decirnos:

Liste que ves engaño colorido

que del arte ostentando los primores

con falsos silogismos de colores

es cauteloso engaño del sentido;

este, en quien la lisonja ha pretendido

excusar de los años los horrores

$y$ venciendo del tiempo los rigores

triunfar de la vejez y del olvido

es un vano artificio del cuidado,

cs una flor al viento delicada,

es un resguardo inutil para el hado:

es una necia diligencia errada,

es un afán caduco $y$, bien mirado,

es cadáver, es polvo, es sombra, es nada."

A la misma razón de ser, a la misma "voluntad de forma" responde la pintura, la escultura, la arquitectura, la música, la poesía. La poesía (con Juana como estrella guiadora) no relata o describe llanamente, sino que necesita complicarse, cargarse de artificios, de símbolos; está convencida de la imposibilidad de ser natural y de la necesidad del "vano artificio". Sabe que la única manera de decir las cosas es metafóricamente y es fiel a esta convicción. Más que cámara fotográfica, es inter-

20 Zapata, Zerón: La Puebla de los Angeles en el siglo xvin. México, Ed. Patria, 1954, p. 83. Cf. Francisco de la Maza: "Decoración simbólica..."

21 Gorozpe: op. cit. Cf. De la Maza: "Decoración simbólica..."

22 Contrato para la factura de la silleria de San Agustín, citado por Romero de Terreros: op. cit. p. 41.

23 Soneto en que procura desmentir los elogios que a un retrato de la poetisa inscribió la verdad, que llama pasión. Cf.: Obras Completas. Estudio, notas y texto revisado por A. Méndez Plancarte. México, Fondo de Cultura Económica, 1951. p. 277. 
DOI: http://dx.doi.org/10.22201/iie.18703062e.1962.31.728

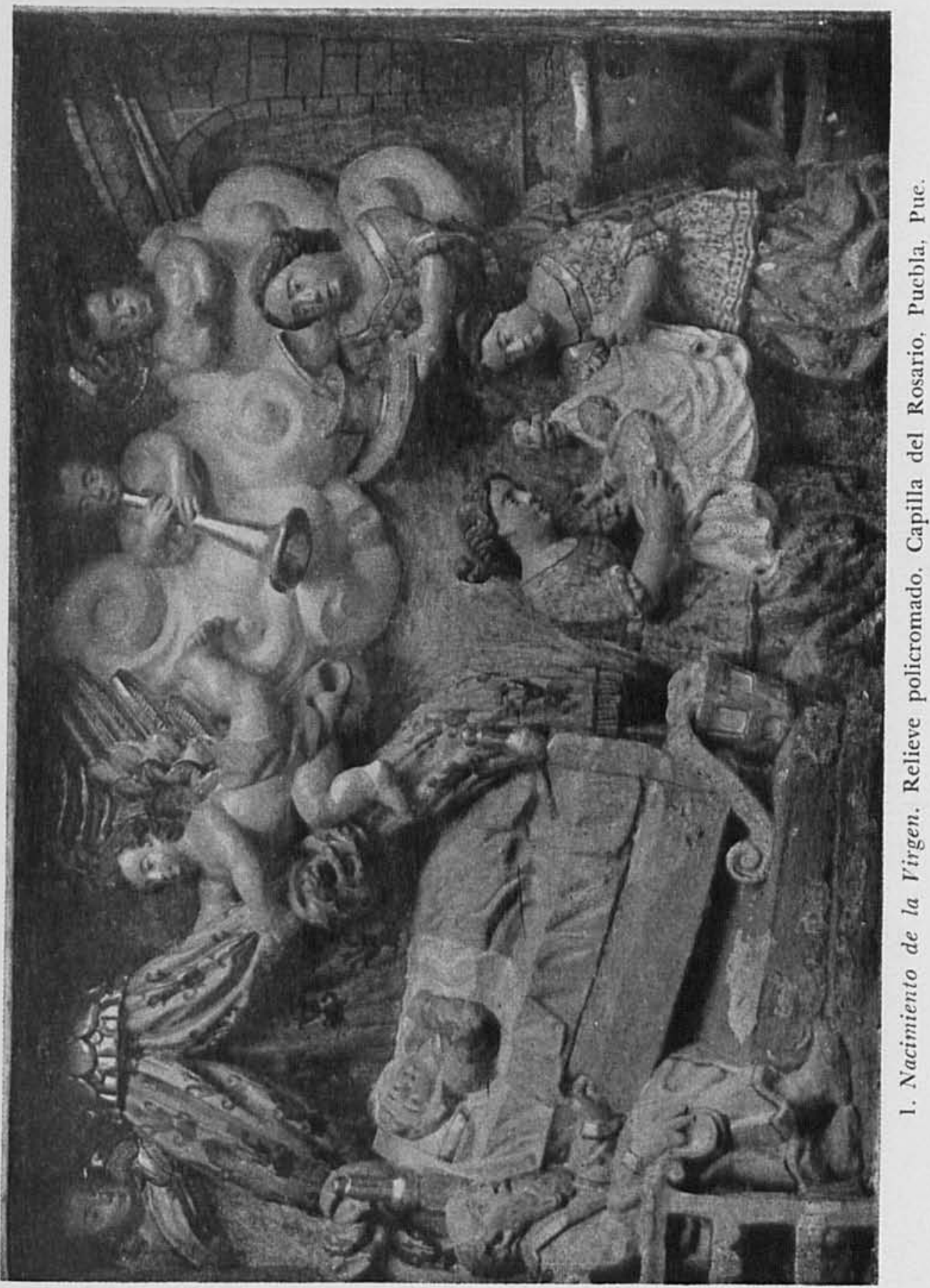


DOI: http://dx.doi.org/10.22201/iie.18703062e.1962.31.728

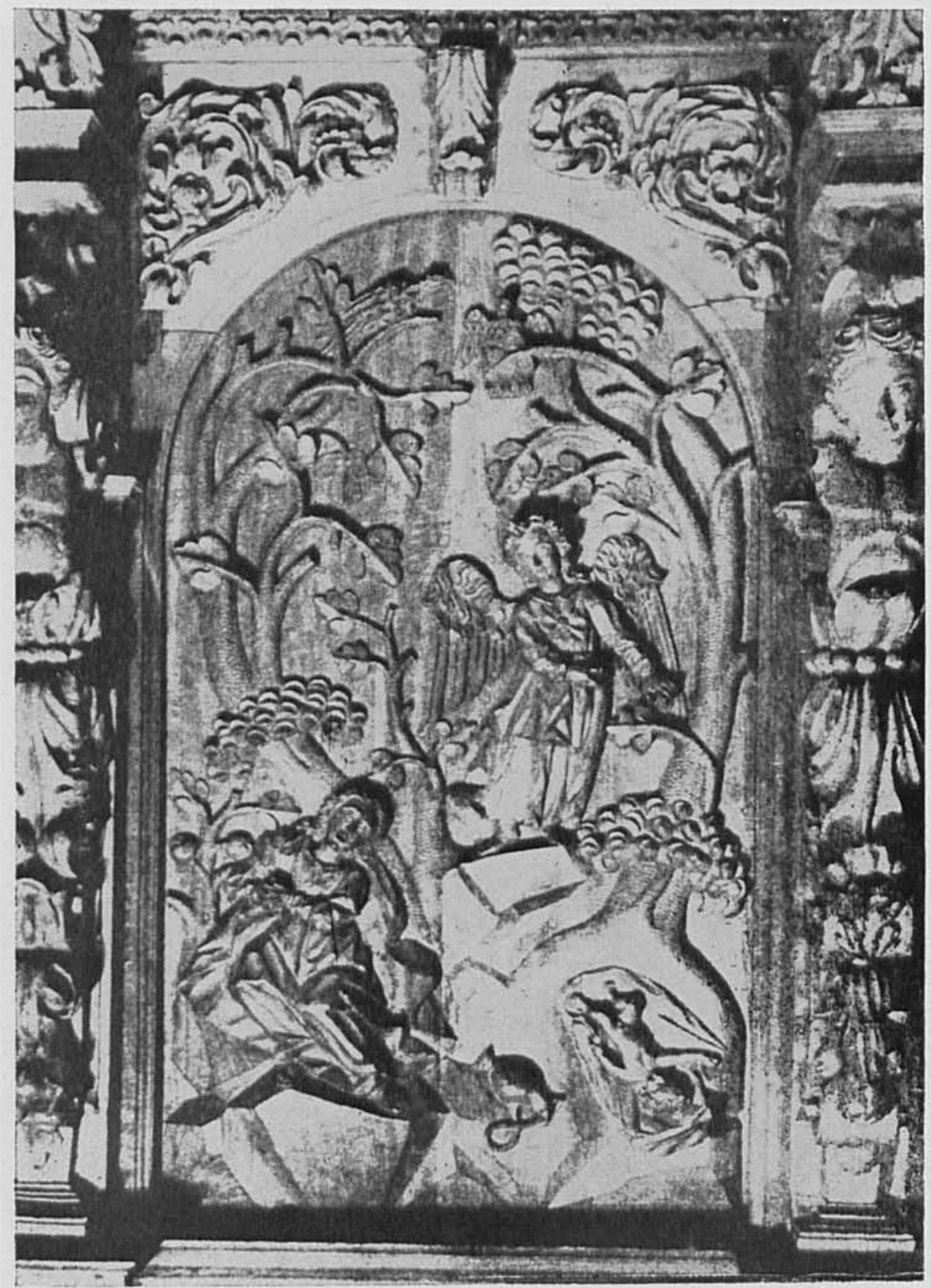

2. Agar y el Angel en el bosque. Sillería de San Agustin. 
DOI: http://dx.doi.org/10.22201/iie.18703062e.1962.31.728

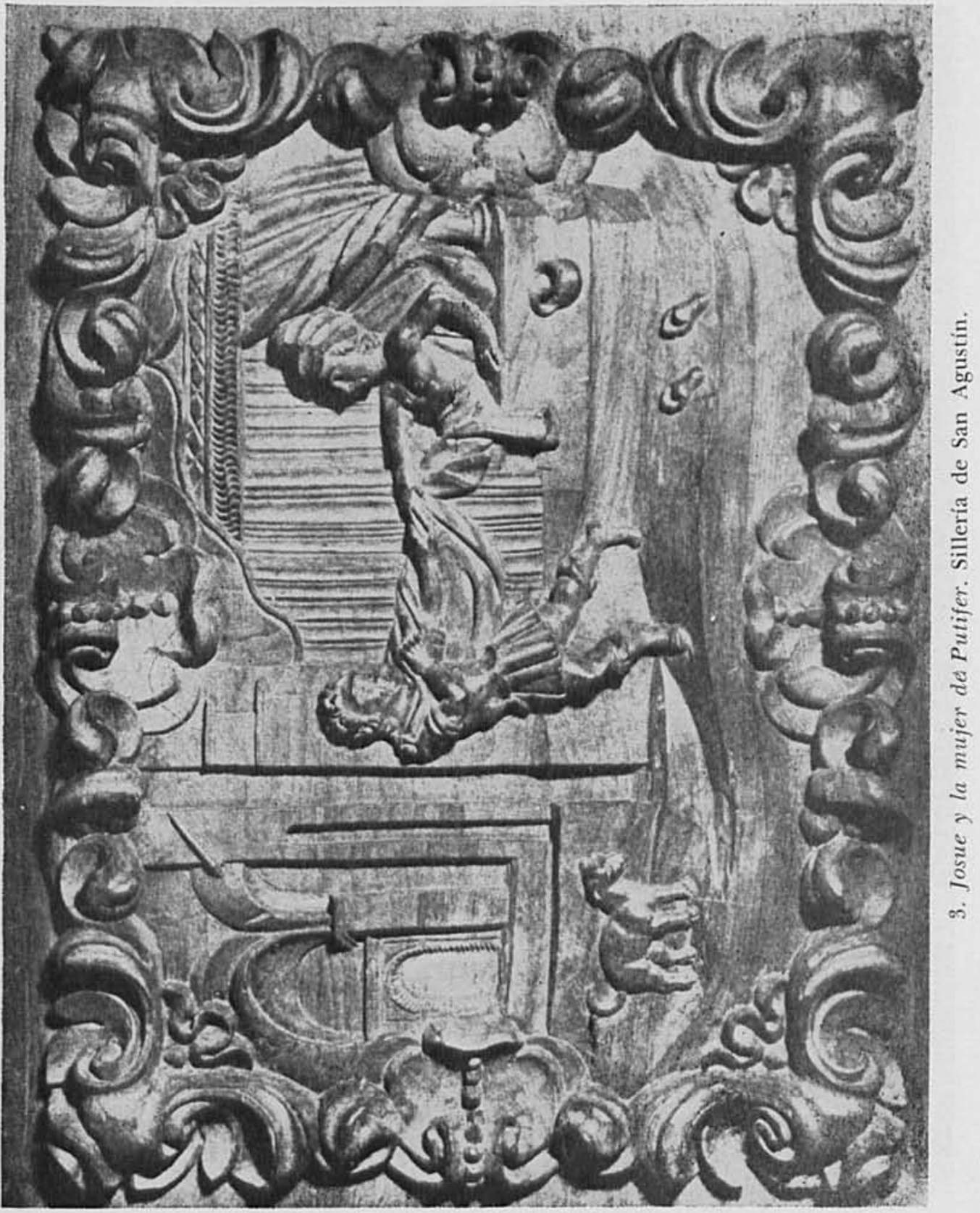


DOI: http://dx.doi.org/10.22201/iie.18703062e.1962.31.728

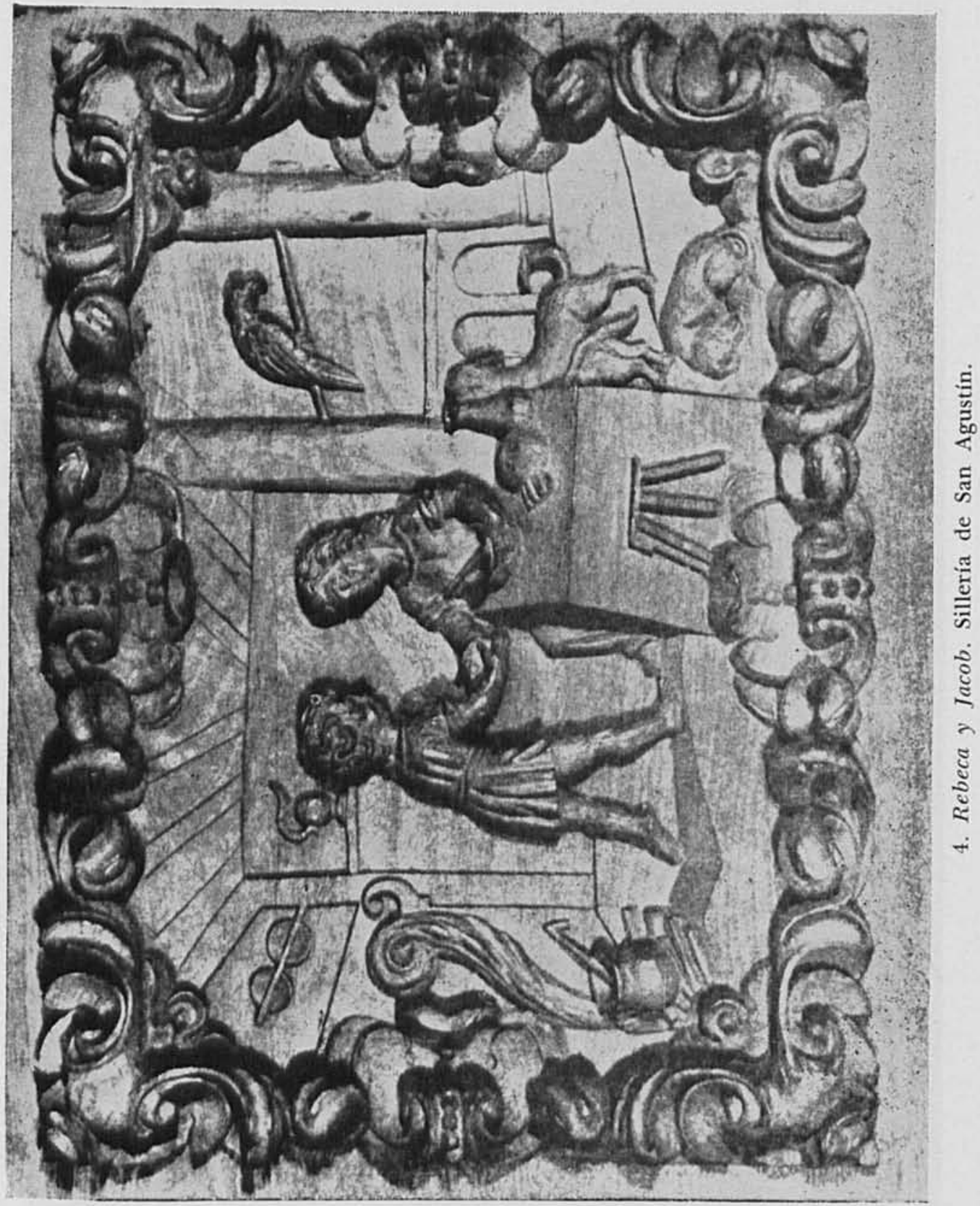


DOI: http://dx.doi.org/10.22201/iie.18703062e.1962.31.728

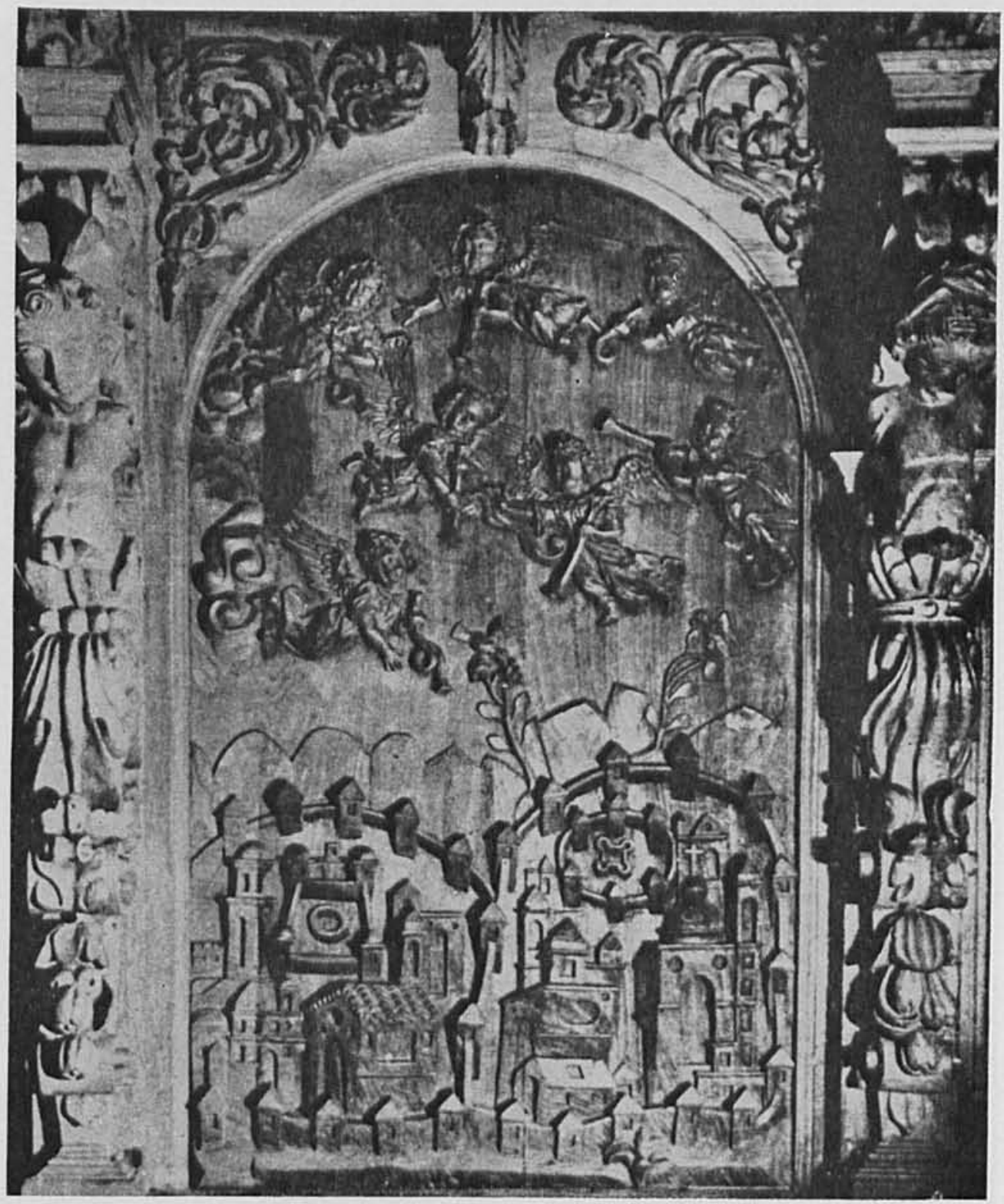

5. Los siete angeles sobre las ciudades, Silleria de San Agustin. 
DOI: http://dx.doi.org/10.22201/iie.18703062e.1962.31.728

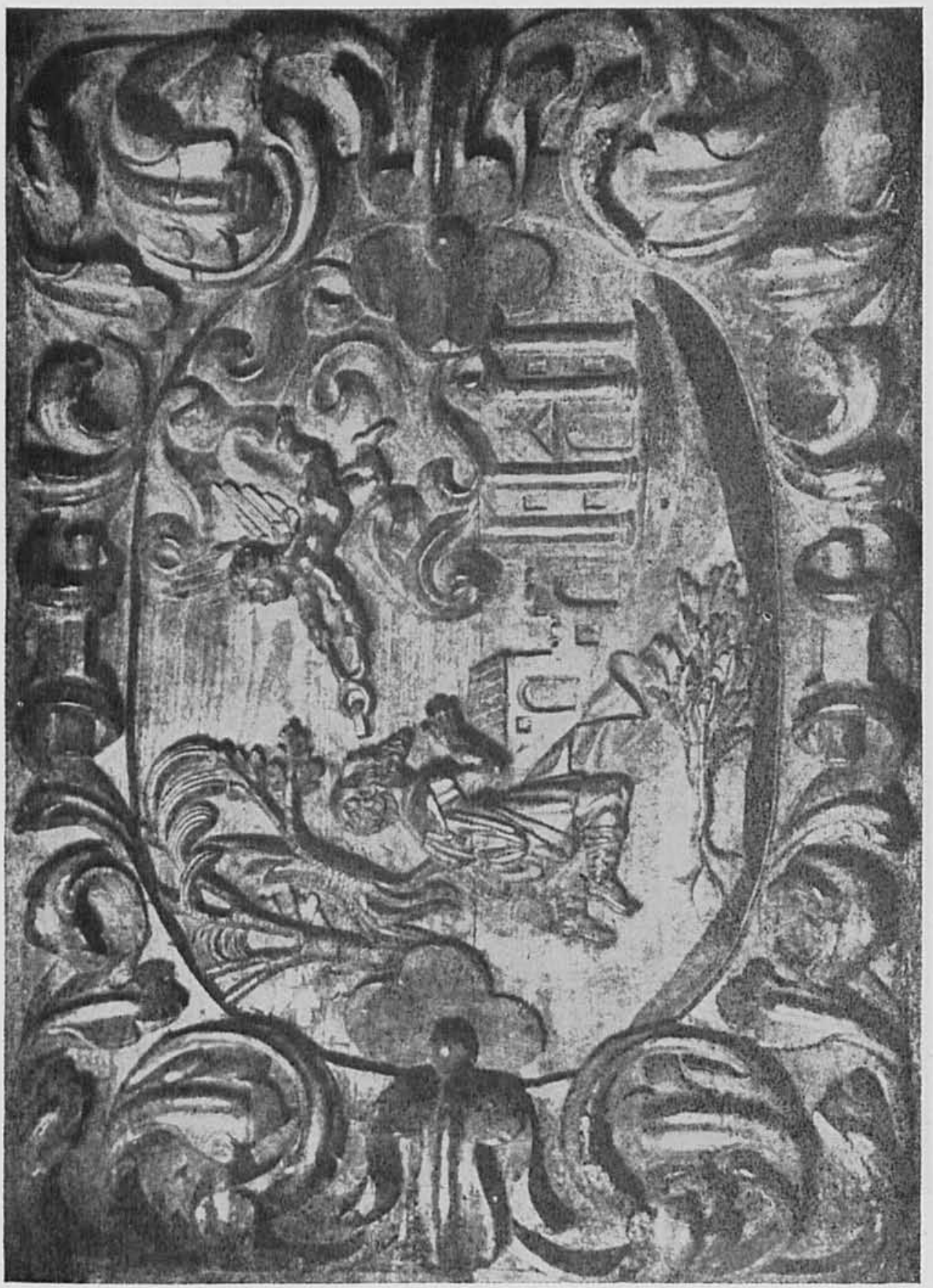

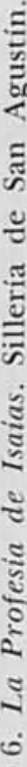




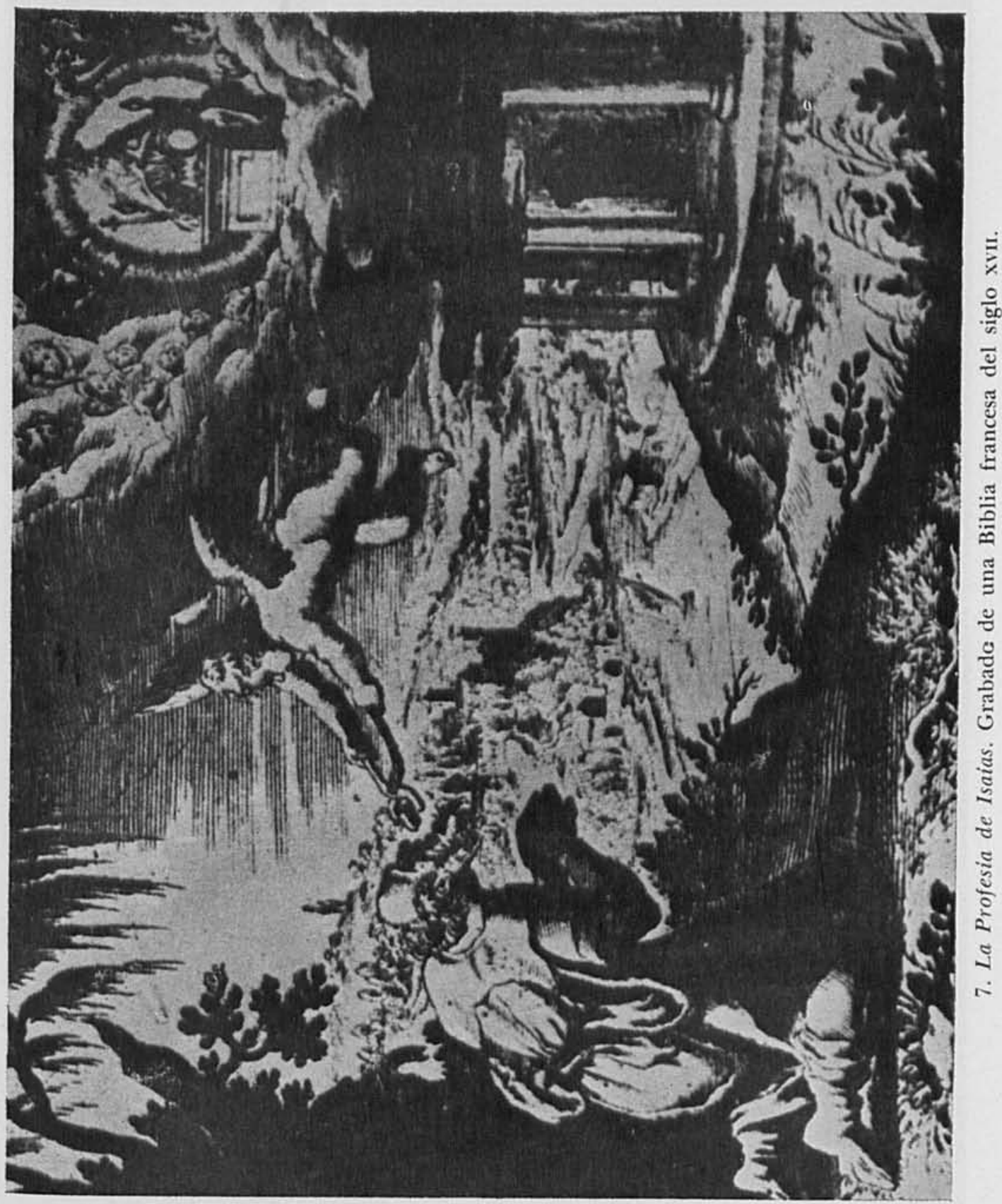




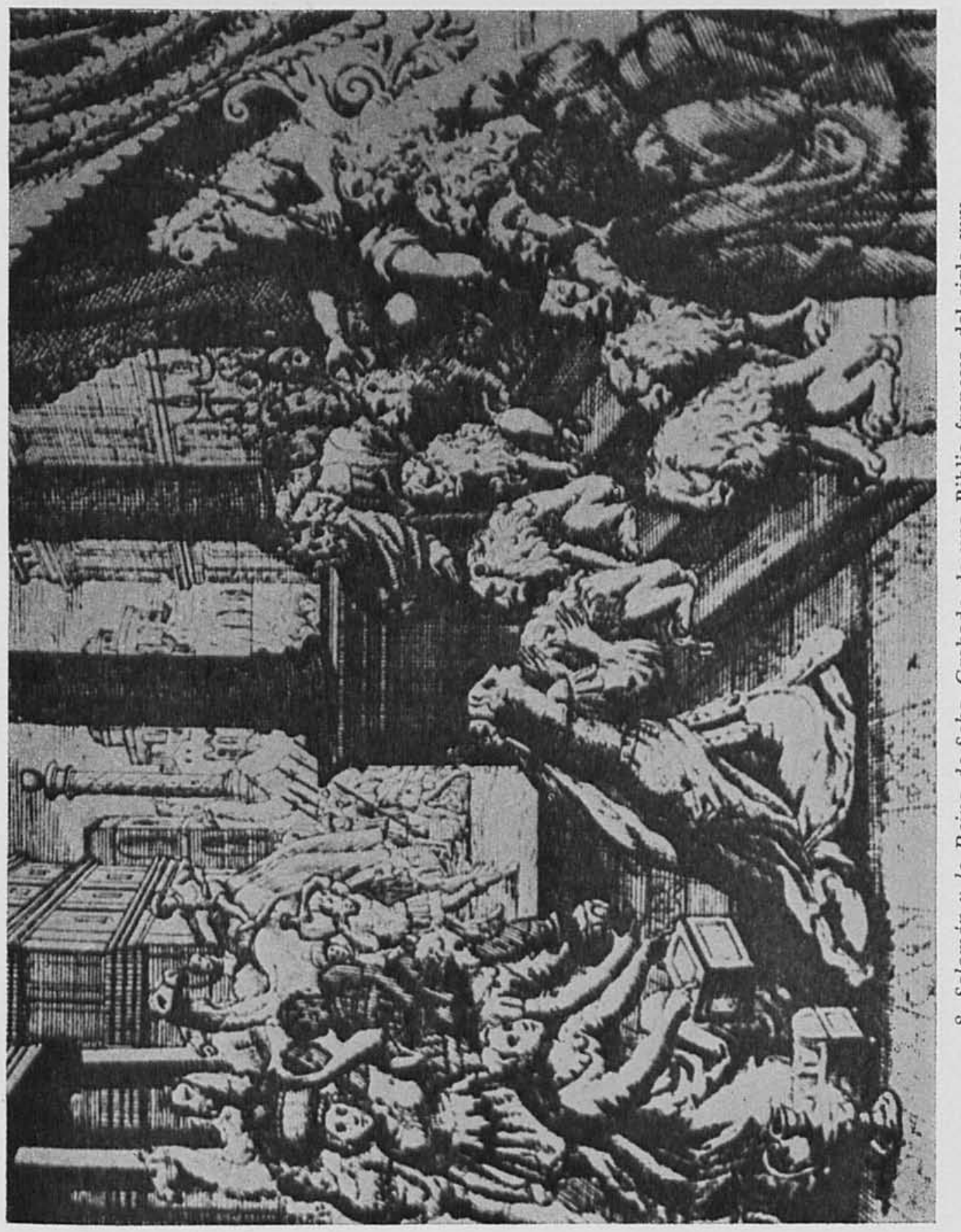


pretadora de signos: del mundo de signos que es la naturaleza. Y sin embargo, arte metafórico y grandilocuente, arte artificioso, el de Nueva España está ligado necesariamente a las representaciones tradicionales de la naturaleza.

En el pequeño relieve de la Capilla del Rosario (Fig. 1) hay una representación alterada de la naturaleza; falsa, es decir, humanizada (o, hasta podemos decir, divinizada). Dentro de su pequeñez y modestia obedece a esa necesidad barroca de complicación, de recargamiento, y, sobre todo, de grandes efectos. La escena de la Natividad de la Virgen se divide casi en dos partes iguales: la de lo que sucede en la tierra, y la irrupción divina en ese hecho que trasciende lo terrestre, representada por esa nube de angelitos (niños, como todos los que decoran la capilla) que bajan tocando trompetas, orando y uno de ellos des. corriendo el dosel que cubre el lecho de Santa Ana. La cama se ve en un relativo escorzo; y este simple hecho nos lleva a una interpretación: el escultor del relieve no tiene la necesidad ni el interés por dar en él una tercera dimensión marcada, por crear una profundidad; parece bastarle para expresarse con los dos planos cercanos (el interior y el exterior) del relieve; el resto de la escena así nos lo muestra. (Otros relieves contemporáneos corresponden a este sentido de la casi bidimensionalidad, por ejemplo, los del "colateral" de Amecameca, muy cercanos formalmente al que estudio.) $\mathrm{Y}$, sin embargo, el escultor no puede librarse de la tradición que imponía una perspectiva en "trompe l'oeil"; así, la cama afecta un escorzo que en justicia no corresponde a la realidad de la intención, consiste sólo en desviar el eje, sin que esto produzca mayores efectos. En las gradas que la sostienen se ve el compromiso que tuvo el autor del relieve: una de ellas sube diagonalmente para ligarse al eje de la cama, pero sin llegar a alcanzar su inclinación, la otra conserva ya plenamente su horizontalidad y corresponde con el sitial de San Joaquín que está en el ángulo inferior izquierdo del recuadro, acomodado perfectamente en él.

Es notable, por otra parte, la falta de "proporción natural" que guardan las figuras del relieve unas con otras. Las mujeres que sostienen a la Virgen son más grandes no sólo que Santa Ana que puede suponerse en un segundo plano sino que San Joaquín, que está en el mismo plano que ellas. Pero el absurdo aparente llega al máximo con los ángeles, niños más grandes que el resto de las figuras de la escena. En el caso de las mujeres la desproporción se justifica porque son ellas quienes sostienen a María, ella sí pequeña, aunque vestida con ropas sobrecargadas, y necesitan atraer la atención en esa importantísima zona del 
recuadro. La importancia de los ángeles niños se explica, como ya queda dicho, porque representan justamente la presencia de lo divino en la escena.

Y sin embargo, lo más revelador de toda ella es el tratamiento dado a las formas. Las nubes en que bajan los ángeles no muestran formas naturales, sino formas absolutamente convencionales, parecen nubes moldeadas en azúcar; hacen unas espirales casi geométricas que se repiten ahí donde el espacio se los permite: no son las nubes que uno puede ver en el aire, sino precisamente unas nubes rehechas, recreadas. Las nubes de esos ángeles, las cortinas del dosel, el extraño gabán de San Joaquín, las sábanas de la cama, las ropas de las sirvientas y el lienzo en el que está la Virgen, todo está tratado a base de líneas convencionales, rígidas, como golpes de hacha ("primitivismo", como diría Moreno Villa). Lo más notable y explícito es tal vez el lienzo que sale de una canastilla, al pie del lecho; en lugar de caer en forma natural, se enrosca al llegar al suelo en una espiral, casi viviente, que repite la espiral del respaldo del sillón y las de las nubes. Esto basta para acabarnos de dar la clave. Un pobre pedazo de trapo no puede caer "naturalmente", sino que afecta esa forma necesaria, convencional, codificada y aceptada.

Muy importante es hacer notar que este anónimo escultor "ingenuo" ha compuesto su aparatosa escena, que a primera vista parecería revuelta, sirviéndose de una sección de oro, la del lada mayor del rectángulo apaisado, en la que se localizan la mujer que sostiene a la Virgen y el más importante de los ángeles, el que toca la trompeta. En el lado menor del rectángulo, la sección áurea, menos clara, se encuetra señalada por la cabeza de la Virgen, el ángulo de la cama de Santa Ana y la barba y hombro de San Joaquín. Es evidente que así quiso el escultor atraer el interés del espectador y centrarlo en la figura más pequeña, pero la más importante: la Virgen.

Los relieves de la sillería del coro de San Agustín responden, igualmente, a las mismas necesidades artísticas. En ellos hay también una interpretación de la naturaleza. Las formas se pliegan a su propio sistema interno. En casi todos hay una perspectiva falsa, doblemente falsa: porque toda perspectiva es en sí una falsedad, y porque alli se toman ciertos elementos de la perspectiva tradicional, pero haciéndolos ineficaces. Esta perspectiva peculiar puede verse perfectamente en la representación de las ciudades, por ejemplo en el recuadro del toque de las siete trompetas apocalípticas (Fig. 5) donde aparecen apenas señalados 
los trazos indispensables para la perspectiva según la tradición, pero con un resultado totalmente diverso; no se rompe de ningún modo el límite real e ideal marcado por los dos planos extremos del relieve, y cada edificio queda representado en su integridad e individualidad (recuérdese lo que queda dicho acerca del carácter analítico de este arte). Al escultor Ocampo no le importó mayormente que en las escenas del Paraiso resultaran más grandes los leones que los elefantes, ni que los pájaros y muchos otros animales fueran totalmente imaginarios. $\mathrm{Ni}$ que parecieran unos animales encima de otros en lugar de estar en un plano posterior. Lo que le importaba era que existieran ciertos elementos indispensables para la escena, símbolos inteligibles, y su "realismo" quedó en segundo término. No es una casualidad tampoco que gran parte de los tableros superiores se refieran al Apocalipsis de San Juan, que por su misma naturaleza es fantástico e irreal.

Especialmente significativo es el hecho de que todas las nubes representadas en todos los tableros, lo mismo aquellas donde se apoya Dios Padre o donde se apoyan los ángeles, que las pequeñas nubes de un paisaje, tienen forma de $S$; la misma $S$ de las nubes de los relieves deI coro de Santo Domingo de Oaxaca y de otros relieves de la época. Son siempre nubes imaginadas, nunca nubes copiadas.

Rafael García Granados encontró que algunos de los tableros pequeños de la sillería estaban no sólo inspirados, sino copiados de los grabados en cobre ejecutados por grabadores franceses de segunda para una Biblia editada en París en el siglo xvir. Esto, que aparentemente disminuiría el valor de la obra de Ocampo y sus ayudantes, nos permite justamente apreciar sus valores propios. Aunque los tableros estén tomados de los grabados en cobre, el lenguaje formal del escultor de la sillería es completamente diferente. Lo que en la Biblia francesa es perspectiva eficaz, en los relieves tiene un sentido diverso. Todo lo que en aquella es manierismo, en éstos se cambia en formas que no por convencionales son menos fuertes y originales. Lo que allá es delicadeza, aquí se cambia en fuerza; y lo que allá son formas muertas, sin mayor significación, aquí cobra un nuevo vigor. El material en el que trabajó Ocampo imponía desde luego un tratamiento diferente y una simplificación; pero es más que eso. La comparación con relieves cercanos a los de la sillería nos permite asegurar que los grabados franceses están "traducidos", adaptados a nuevas necesidades de expresión, y adquieren un significado completamente diferente. Han entrado en un nuevo mundo de formas, que obedece, indudablemente, a diferentes necesidades anímicas. El sis- 
tema formal de la sillería (es decir, el sistema formal de la Nueva España del siglo xvi) se ha tragado aquellas figuras grabadas que no fueron más que un punto de partida. Naciendo de ellas se ha llegado a un resullado propio y diferente. ${ }^{24}$ (Figs. 6,7 y 8 ).

Para el artífice de Nueva España, el arte era una especie de “juego de formas", juego con formas. Se trataba en realidad de un malabarismo para sacar partido de elementos ya dados y repetidos. Su problema era agotar las posibilidades de una serie de convenciones estereotipadas. La novedad del arte era fatigar las combinaciones posibles de una serie de reglas y usos invariables. A este "vano artificio", "flor al viento delicada", responde la mayoría de las creaciones artísticas de nuestro barroco. La inventiva no estaba tanto en encontrar nuevas formas, sino en llevar a todas sus consecuencias las ya dadas. Así podemos explicarnos aquellos certámenes literarios donde se señalaba el tipo de composición que debía utilizarse, el tema, la idea, y a veces hasta las consonantes finales de los versos: el mejor era quien podía, con elementos tan rígidos, hacer algo realmente nuevo y diferente. ${ }^{25}$

Es también el sentido de los retablos y de las fachadas, siempre repetidos y siempre novedosos. $\mathrm{Y}$ es, en fin, el sentido de estos relieves que estudio; unas formas sabidas y codificadas, de las que sin embargo era todavía posible obtener valores expresivos de calidad extraordinaria.

24 Cf. op. cit., en la nota 12.

25 Vid. Triunfo Parténico... descríbelo D. Carlos de Sigüenza y Góngora. México, Ed. Xóchitl, 1945; y Pascual Buxó, José: Arco y Certamen de la Poesia Mexicana Colonial, siglo xvir. Jalapa, Universidad Veracruzana, 1959. (Cuadernos de la Facultad de Filosofía y Letras, 2.) 